\title{
Revealed access to haemodialysis facilities in northeastern Iran: Factors that matter in rural and urban areas
}

\author{
Behzad Kiani, ${ }^{1}$ Nasser Bagheri, ${ }^{2}$ Ahmad Tara, ${ }^{3}$ Benyamin Hoseini, ${ }^{4}$ Hamed Tabesh, ${ }^{1}$ \\ Mahmood Tara ${ }^{1}$ \\ ${ }^{1}$ Department of Medical Informatics, Mashhad University of Medical Sciences, Mashhad, Iran; \\ ${ }^{2}$ Department of Health Services Research and Policy, College of Health and Medicine, Biology and \\ Environment, Australian National University, Canberra, Australia; ${ }^{3}$ Department of Nephrology, Shahid \\ Modarres Hospital, Shahid Beheshti University of Medical Sciences, Tehran; ${ }^{4}$ Department of Health \\ Information Technology, Neyshabur University of Medical Sciences, Neyshabur, Iran
}

\begin{abstract}
Poor access to haemodialysis facilities is associated with high mortality and morbidity rates. This study investigated factors affecting revealed access to the haemodialysis facilities considering patients living in rural and urban areas without any haemodialysis facility (Group A) and those living urban areas with
\end{abstract}

Correspondence: Mahmood Tara, Department of Medical Informatics, Faculty of Medicine, Mashhad University of Medical Sciences, Mashhad, Iran.

Tel: +985138002428 - Fax: +985138002445.

E-mail: smtara@gmail.com

Key words: Accessibility; Haemodialysis; Potential access; Revealed access; Iran.

Acknowledgments: the authors would like to make special thanks to Dr. Mohsen Shahriari for his contribution to data gathering, as well as all the nurses who work in the haemodialysis facilities in north Khorasan Province of Iran.

Contributions: BK, BH, data collecting; $\mathrm{BK}$, HT analysing; BK manuscript writing; MT, AT, NB, manuscript reviewing; MT, AT, NB study designing.

Conflict of interest: the authors declare no potential conflict of interest.

Funding: the work was supported by a grant [931059] from Mashhad University of Medical Sciences Research Council.

Received for publication: 11 May 2017.

Revision received: 6 July 2017.

Accepted for publication: 8 July 2017.

(C) Copyright B. Kiani et al., 2017

Licensee PAGEPress, Italy

Geospatial Health 2017; 12:584

doi:10.4081/gh.2017.584

This article is distributed under the terms of the Creative Commons Attribution Noncommercial License (CC BY-NC 4.0) which permits any noncommercial use, distribution, and reproduction in any medium, provided the original author(s) and source are credited. haemodialysis facilities (Group B). This study is based on selfreported Actual Access Time (AAT) to referred haemodialysis facilities and other information regarding travel to haemodialysis facilities from patients. All significant variables on univariate analysis were entered into a univariate general linear model in order to identify factors associated with AAT. Both spatial (driving time and distance) and non-spatial factors (sex, income level, caregivers, transportation mode, education level, ethnicity and personal vehicle ownership) influenced the revealed access identified in Group A. The non-spatial factors for Group B patients were the same as for Group A, but no spatial factor was identified in Group B. It was found that accessibility is strongly underestimated when driving time is chosen as accessibility measure to haemodialysis facilities. Analysis of revealed access determinants provides policymakers with an appropriate decision base for making appropriate decisions and finding solutions to decrease the access time for patients under haemodialysis therapy. Driving time alone is not a good proxy for measuring access to haemodialysis facilities as there are many other potential obstacles, such as women's special travel problems, poor other transportation possibilities, ethnicity disparities, low education levels, low caregiver status and low-income.

\section{Introduction}

The prevalence of End Stage Renal Disease (ESRD) is increasing in Iran and across the world (Mousavi et al., 2014). The total number of patients with ESRD condition was 27,000 in Iran in 2015 (Mousavi et al., 2014). Haemodialysis is the main treatment for this condition. This machine-operated process removes fluid and waste from the blood and rectifies the electrolyte imbalance (Hay, 1995). Most patients have to be dialysed three times week, making it necessary for them to travel to a haemodialysis facility between 140 and 160 times per year (Stephens et al., 2013). It has already been proven that poor access to haemodialysis facilities for these patients is associated with poor health outcomes, such as high mortality and morbidity rates (Moist et al., 2008). Access to health services is defined as the ease with which the services can be used by people whenever and wherever needed (McLafferty, 2003). It has five main dimensions: accessibility, availability, accommodation, affordability and acceptability (Penchansky and Thomas, 1981). The accessibility and availability dimensions are usually related to geographical factors; hence 
they are spatial dimensions (Mao and Nekorchuk, 2013). Affordability, accommodation and acceptability, which are independent of geographical conditions, are the non-spatial dimensions (Guagliardo, 2004). Additionally, access can be divided into two broad categories: Potential access, which is simply defined as the presence of enabling resources, and Revealed access, which is the actual use of services (Andersen, 1995).

In recent studies, accessibility to health-care services is commonly measured by driving time between the patient's residence and the closest health-care facility (Matsumoto et al., 2013; Stephens et al., 2013; Casas et al., 2016). Revealed access differs from potential access in a number of ways. For example, haemodialysis patients may have a short driving time to access the nearest haemodialysis facility, but they may decide to go to another centre because of ethnic disparities (Saunders et al., 2014), resource availability (Just et al., 2008), flexibility in planning dialysis time, sense of security, physical space, noise, pre-dialysis education or involvement in the choice of modality (Lee et al., 2008). Therefore, if the nearest haemodialysis facility is the preferred haemodialysis facility (is assumed), the potential access should be measured (Miller et al., 2014). In addition, previously published methods in estimating the driving time between patient residence location to the haemodialysis services may not show the Actual Access Time (AAT) precisely due to other confounding factors, e.g., transportation mode (Neutens, 2015), car ownership (Lovett et al., 2002) and income (Wang and Luo, 2005). Therefore, a proper method of measuring AAT as revealed access measurement to the haemodialysis services is needed.

To compensate for this knowledge gap, this study aimed to measure an AAT index as proxy for revealed accessibility of haemodialysis patients to haemodialysis facilities as well as the association between AAT and other factors that may influence accessibility.

\section{Materials and Methods}

In this research, revealed access was measured and self-reported AAT to haemodialysis facilities was used as the revealed access measurement.

\section{Study region and data}

This cross-sectional study of haemodialysis patients was carried out in northern Khorasan Province of Iran with an estimated population of 919,000 in 2015 (Wikipedia, 2016). This paper is the continuation of a recently published paper (Kiani et al., 2017). The study area is displayed on a point density map (Figure 1). Two hundred and three patients were under haemodialysis in the area but only 168 of them met both inclusion criteria and were willing to participate in the study.

\section{Ethics approval and consent to participate}

This study was approved under the code IR.MUMS.RES. 1393.756 by the Ethical Committee of Mashhad University of Medical Sciences in Mashhad, Khorasan Province, Iran. All patients completed a consent form for participating in the study.

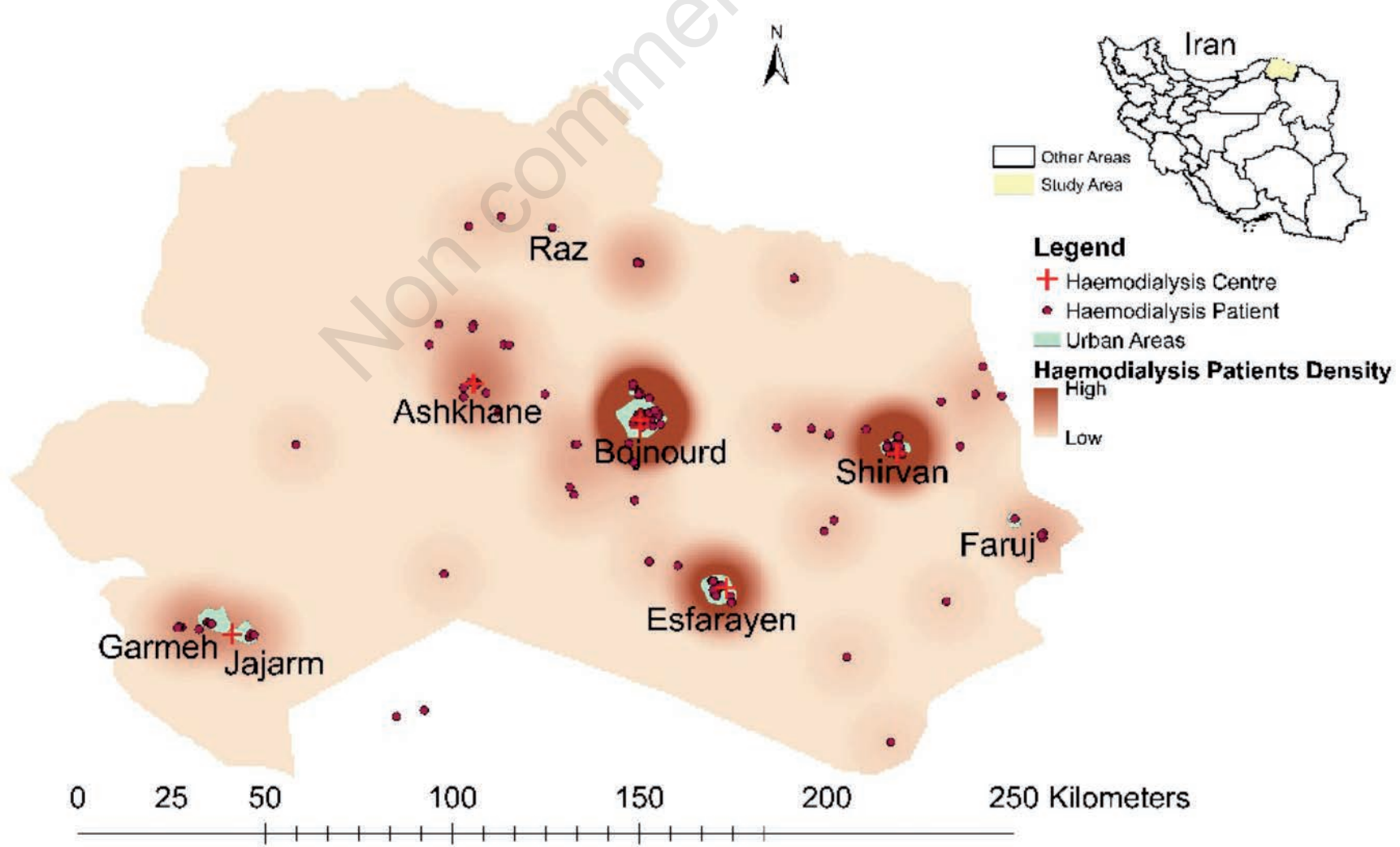

Figure 1. Geographical distribution of patients needing haemodialysis and service centres displayed on a point density map in northern Khorasan Province, Iran (December 2015). 


\section{Inclusion criteria}

We included only patients meeting all the following criteria: i) the patient had agreed to participate in an interview; ii) the patient had to be dialysed at least one time a week; iii) the patient had to be at least two months under haemodialysis; iv) the patient or his/her caregiver was able to communicate with researchers.

\section{Data collection}

We developed and used the census sampling method with structured questions for data collection. The validity of the questions was confirmed by two native experts (a medical information specialist and a nephrologist). According to literature review and expert opinion, the following variables were chosen for the collection of patient data: Gender (Roderick et al., 1999); Age (Rodriguez et al., 2013); Residence (Rodriguez et al., 2013); Occupation (Rodriguez et al., 2013); Education (Rodriguez et al., 2013; Calice-Silva et al., 2015); Income (Rodriguez et al., 2013); Ethnicity (Rodriguez et al., 2013; Saunders et al., 2014); Transportation mode (Murray, 2008; Prakash et al., 2010); Driving time (White et al., 2006; Matsumoto et al., 2013; Stephens et al., 2013); Driving distance (Stephens et al., 2013); Car ownership; Patient's caregiver status.

The patients were asked to give AAT and other information regarding travel to the haemodialysis facilitiy of their choice. Driving time and distance from home to the referred haemodialysis facility were calculated using Google Map for each patient. When more than one path was offered by GoogleMaps, the shortest route was chosen as it is known as potential access. For patients travelling to haemodialysis facilities with their own vehicles, fuel was included in the travel cost. The estimated fuel was 10 litres per hundred $\mathrm{km}$ for cars and three litres for motorcycles. Since there was a measurement bias in self-reported income and there is no validated index for Iranian household income, the Townsend deprivation index (Townsend, 1987) adjusted by local experts, was used for estimating patient income levels (Table 1).

\section{Statistical analysis}

The distribution of variables was skewed even after log transformation. Therefore, we used median and inter quartile range (IQR) instead of mean and standard deviation (SD) for descriptive analyses. Moreover, non-parametric statistical tests were used for inferential statistics.

Data for patients living in rural and urban areas without any haemodialysis facility (Group A) and those living urban areas with haemodialysis facilities (Group B) were analysed separately. The effect of all variables on AAT, as a response variable for both Groups A and B was tested. The Man Witney test (Nachar, 2008) for examining the effect of binary variables on AAT and the Kruskal-Wallis test (Elliott and Hynan, 2011) were used for determining the effect of other nominal variables on AAT. The linear, quadratic, and cubic associations were examined to determine the relationship between AAT and other numerical variables, then the best model (with the maximum of $\mathrm{R}^{2}$ ) was chosen.
All significant univariate analysis variables were entered into the univariate general linear model (GLM) to identify factors associated with AAT. The GLM for Group A patients was developed by including AAT as a dependent variable and two covariates: distance and driving time, while car ownership, education level, income level, sex, ethnicity, patient caregiver status and transportation mode comprised fixed factors. The univariate GLM for Group B patients was partly different and included car ownership, education level, income level, sex, ethnicity, patient caregiver status and transportation mode as fixed factors. Naturally, the AAT was also the dependent variable for Group B.

All these analyses were performed twice. First, the AAT to haemodialysis facilities, followed by the Actual Return Time (ART) from the haemodialysis facility to the patient's home. The significant threshold for all calculations was set at 0.05 . We used the SPSS Version 16 for statistical analysis, ArcGIS v. 9.3, and Google Map for spatial analyses.

\section{Spatial analysis}

To visualise the difference between AAT as a revealed accessibility measurement and driving time as a potential accessibility measurement, both these values were interpolated. Spatial interpolation is the process of using points with known values to estimate values at other, unknown points. We used the Inverse Distance Weighting algorithm for interpolation (Jia et al., 2016).

\section{Results}

The general characteristics of sample populations are shown in Tables 2 and 3. According to the former, some patients had changed their home to get better access to haemodialysis (one in Group A and 12 in Group B).

Driving time and the AAT score are summarised by a box-plot in Figure 2. This figure shows a doubling of the AAT score compared to the driving time in groups A and B. Further, it took patients in Group A three times longer than patients in group B to reach their assigned haemodialysis facilities. The Mann-Whitney $\mathrm{U}$ test showed that there was a statistically significant difference in the AAT score between the groups, Man-Whitney $U=940.000$, $\mathrm{P}=0.000$, with a mean rank AAT score of 115.00 for Group A and 57.00 for Group B.

\section{Factors influencing Actual Access Time}

The GLM analysis of group A showed that driving distance and driving time as spatial factors with sex, income level, existing patient's caregiver, transportation mode, education level, ethnicity, and personal vehicle ownership as the non-spatial factors affecting the AAT (Table 4); moreover, the results of the model showed that the identified factors determined the AAT in $90 \%$ of the cases $\left(\mathrm{R}^{2}=0.906\right)$. In other words, $90 \%$ of changes in the response variable (AAT) in Group A could be explained by these factors.

Table 1. Estimation of the household income level of the haemodialysis patients in northern Khorasan Province, Iran.

Family status Income level

The patient or the head of the household has a job; there is a car in the family; and they are house owners

High

The patient or the head of the household does not have a job; there is no car in the family; and they do not own a house

Low

Other patients

Middle 
The GLM analysis of group B showed that the non-spatial factors were the same as those identified for Group A (Table 5); furthermore, the results of the model showed that the identified factors determined the AAT in $95 \%$ of the cases $\left(\mathrm{R}^{2}=0.951\right)$. In other words, $95 \%$ of changes in the response variable (AAT) in Group B could be explained by these factors. Table 5 shows that none of the spatial factors (driving distance and driving time) were identified as factors affecting the AAT.

\section{Comparison between Actual Access Time and Driving Time}

AAT and driving time were compared to visualise the accessibility to haemodialysis facilities. Figure 3 shows the interpolated AAT as a revealed accessibility index and the interpolated driving time as a potential accessibility index to visualise the access to haemodialysis facilities at the regional level.

\section{Comparison between Actual Access Time and Actual Return Time}

The results observed for AAT and ART were similar to that between AAT and driving time, i.e. there was a significant positive correlation between AAT and ART $(r=0.946, \mathrm{P}<0.001)$.

\section{Discussion}

Cities in northern Khorasan Province are small and do not have heavy traffic. Our study showed that spatial factors are not the main determinants of health care access in urban area with having haemodialysis services. However, for the Group A patients, the

Table 2. General characteristics of the haemodialysis patients in northern Khorasan Province, Iran (December 2015).

\begin{tabular}{|c|c|c|c|}
\hline Characteristic & $\begin{array}{l}\text { All patients } \\
\text { (n) }\end{array}$ & $\begin{array}{c}\text { Group A } \\
\text { (n) }\end{array}$ & $\begin{array}{c}\text { Group B } \\
\text { (n) }\end{array}$ \\
\hline $\begin{array}{l}\text { Gender } \\
\text { Male } \\
\text { Female }\end{array}$ & $\begin{array}{l}97 \\
70\end{array}$ & $\begin{array}{l}41 \\
28\end{array}$ & $\begin{array}{l}56 \\
42\end{array}$ \\
\hline $\begin{array}{l}\text { Occupation } \\
\text { Yes } \\
\text { No }\end{array}$ & $\begin{array}{r}27 \\
140\end{array}$ & $\begin{array}{r}9 \\
60\end{array}$ & $\begin{array}{l}18 \\
80\end{array}$ \\
\hline $\begin{array}{l}\text { Education } \\
\text { Illiterate } \\
\text { Ability to read and write } \\
\text { High school or diploma } \\
\text { Tertiary }\end{array}$ & $\begin{array}{l}74 \\
55 \\
30 \\
11\end{array}$ & $\begin{array}{r}38 \\
22 \\
7 \\
2\end{array}$ & $\begin{array}{r}36 \\
33 \\
23 \\
9\end{array}$ \\
\hline $\begin{array}{l}\text { Ownership of personal vehic } \\
\text { Yes } \\
\text { No }\end{array}$ & $\begin{array}{r}56 \\
111\end{array}$ & $\begin{array}{l}11 \\
58\end{array}$ & $\begin{array}{l}45 \\
53\end{array}$ \\
\hline $\begin{array}{l}\text { Income level } \\
\text { Low } \\
\text { Middle } \\
\text { High }\end{array}$ & $\begin{array}{l}61 \\
67 \\
39\end{array}$ & $\begin{array}{l}31 \\
28 \\
10\end{array}$ & $\begin{array}{l}30 \\
39 \\
29\end{array}$ \\
\hline $\begin{array}{l}\text { Relocation due to dialysis } \\
\text { Yes } \\
\text { No }\end{array}$ & $\begin{array}{r}13 \\
155\end{array}$ & $\begin{array}{r}1 \\
68\end{array}$ & $\begin{array}{l}12 \\
87\end{array}$ \\
\hline Total & 168 & 69 & 99 \\
\hline
\end{tabular}

spatial factors had an effect on AAT because these patients had to spend a longer time travelling to the health care facility. However, this is an contended issue, Thompson et al. (2012) for example, have shown that distance was also an important factor for urban haemodialysis patient travel, while Smith et al. (1985) report that travel time to the place of treatment is a relatively unimportant aspect of the care of haemodialysis patients in metropolitan areas. It seems that the association between spatial factors and the AAT varies in urban areas and depend on other factors such as traffic and the area of the city. Therefore, different studies may have different results and policymakers should consider these issues when planning and/or modifying haemodialysis care to unmet areas in both urban and rural areas. Some earlier studies, for example Salgado et al. (2011) and Faruque et al. (2012), worked on some models to minimise inequities in haemodialysis facilities distribution through finding new facility locations. The work in our study area presented here also emphasises the need for such studies.

This study identified that non-spatial factors affecting the AAT for patients in groups A and B are the same. The fact that females

Table 3. Descriptive attributes of the sample population (patients of Group A and B).

\begin{tabular}{lccccc} 
Characteristic & Group & Min & Median & IQR & Max \\
Age (year) & A & 16 & 48 & $38-57$ & 84 \\
& B & 16 & 53 & $41-63$ & 83 \\
AAT (min) & A & 10 & 45 & $30-60$ & 210 \\
& B & 5 & 15 & $10-20$ & 60 \\
\hline ART (min) & A & 10 & 45 & $30-60$ & 210 \\
& B & 5 & 15 & $10-20$ & 60 \\
AAT + ART (min) & A & 20 & 90 & $60-120$ & 420 \\
& B & 10 & 30 & $20-40$ & 120 \\
\hline DD to dialysis facility (km) & A & 2 & 19 & $8-36$ & 110 \\
& B & 1 & 3 & $2-5$ & 13 \\
DD to home (Km) & A & 2 & 19 & $9-38$ & 111 \\
& B & 1 & 3 & $2-5$ & 13 \\
\hline Total DD (Km) & A & 4 & 38 & $17-74$ & 221 \\
& B & 2 & 6 & $4-10$ & 26 \\
DT to dialysis facility (min) & A & 5 & 20 & $12-32$ & 101 \\
& B & 2 & 8 & $5-10$ & 22 \\
\hline DT to home (min) & A & 5 & 21 & $13-33$ & 102 \\
& B & 2 & 8 & $5-10$ & 21 \\
Total DT (min) & A & 10 & 40 & $25-66$ & 203 \\
& B & 4 & 16 & $10-20$ & 43 \\
\hline Cost of travel to dialysis & A & 0 & 3500 & $2500-6500$ & 25000 \\
facility (Toman/USD) & & & $(\$ 0.92)$ & $(\$ 0.66-1.71)$ & $(\$ 6.58)$ \\
& B & 0 & 1256 & $240-2500$ & 6000 \\
Cost of returning home & A & 0 & 3500 & $2500-6500$ & 25000 \\
(Toman/USD) & & & $(\$ 0.92)$ & $(\$ 0.66-1.71)$ & $(\$ 6.58)$ \\
& B & 0 & 1320 & $300-2500$ & 6000 \\
Total cost (Toman/USD) & A & 0 & 7000 & $4300-12770$ & 50000 \\
& & & $(\$ 1.84)$ & $(\$ 1.13-3.36)$ & $(\$ 13.16)$ \\
& B & 0 & 2576 & $520-5000$ & 12000 \\
& & & $(\$ 0.68)$ & $(\$ 0.137-1.31)$ & $(\$ 3.16)$ \\
& A & 2 & 34 & $10-64$ & 216 \\
& B & 2 & 36 & $9-60$ & 180 \\
\hline
\end{tabular}

IQR, interquartile range; AAT, actual access time; ART, actual return time; DD, driving distance; DT, driving time; USD, US dollar. 
in Group A had a higher AAT score than males may be related to the fact that Iranian women are less able to commute, especially when travelling from a remote area to the city. Dialysis policymakers can plan for women who come from remote or rural areas to haemodialysis facilities by providing transportation services. Additionally, such a service can reduce the negative impact of other factors on the AAT score, and a better transportation system may eliminate the income effect, transportation mode and car ownership. It should be investigated if this approach would be a way to reduce the AAT score for haemodialysis patients and if so, whether it would be cost-efficient.

To the best our knowledge, this is the first study in Iran using the AAT for identifying accessibility to haemodialysis facilities. Moist et al. (2008), in contrast to our study, showed that employment status, family support and age correlated with self-reported one-way travel time. However, like our study, Saunders et al. (2014) showed that proximity to haemodialysis facility did not alone indicate access as other factors, e.g., ethnicity, could also affect access. Matsumoto et al. (2013) used driving time, Salgado et al. (2011) driving distance and Saunders et al. (2014) Euclidean distance (the straight-line distance between two points) for measuring accessibility to haemodialysis facilities. Our study, however, showed that each of these measures used alone would not be

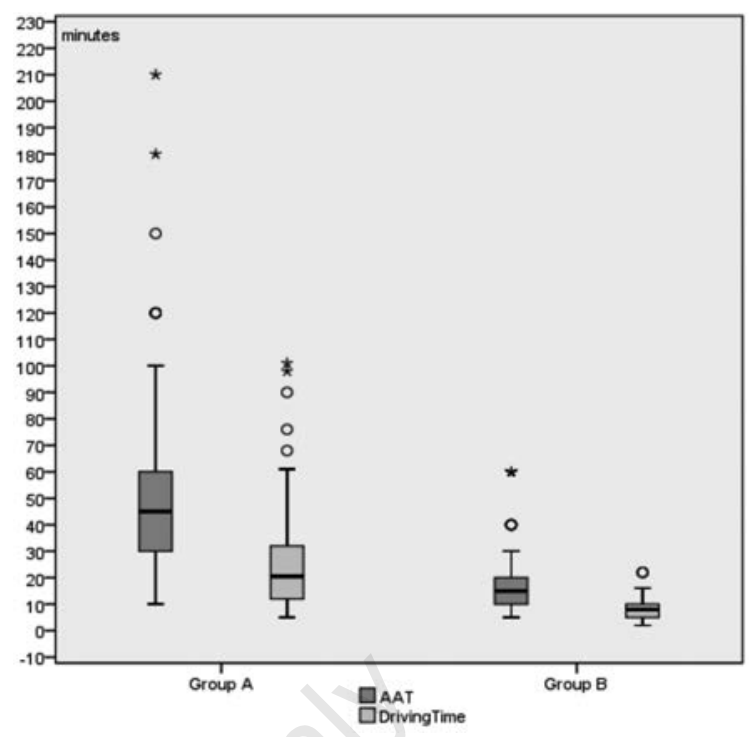

Figure 2. Driving time as potential access measurement $v s$ actual access time as revealed access measurement. Stars and circles show the outlier patients.

Table 4. General linear model for indicating factors affecting actual access time in Group $A\left(R^{2}=0.906\right)$.

\begin{tabular}{|c|c|c|c|c|c|}
\hline Source & Type, sum of squares ${ }^{\circ}$ & Degree of freedom & Mean square & F-test value & $\begin{array}{c}\text { Significance } \\
\text { (P value) }\end{array}$ \\
\hline Corrected model & 115037.580 & 35 & 3286.788 & 9.067 & 0.029 \\
\hline Intercept & 25934.659 & 1 & 25934.659 & 71.546 & 0.000 \\
\hline Cubic of DD & 403.086 & 1 & 403.086 & 1.112 & 0.000 \\
\hline Cubic of DT & 0.012 & 1 & 0.012 & 0.000 & 0.000 \\
\hline Vehicle ownership & 1398.883 & 1 & 1398.883 & 3.859 & 0.000 \\
\hline Sex & 2129.384 & 1 & 2129.384 & 5.874 & 0.000 \\
\hline Transportation mode & 1976.466 & 3 & 658.822 & 1.817 & 0.000 \\
\hline Income level & 1139.329 & 2 & 569.665 & 1.572 & 0.000 \\
\hline Education level & 2030.654 & 3 & 452.000 & 2.567 & 0.000 \\
\hline Ethnicity & 1057.000 & 3 & 524.000 & 3.254 & 0.000 \\
\hline Patient caregiver & 2129.384 & 1 & 569.665 & 3.254 & 0.000 \\
\hline
\end{tabular}

$\mathrm{DD}$, driving distance; DT, driving time. ${ }^{\circ}$ The predictive power of the model with all the other variables except the one being tested (in essence, every variable in the model is tested in light of every other variable in the model, which means that main effects are tested in light of interaction variables as well as in light of other main effects). If the P value for the F-test of the overall significance test is less than the 0.05 , the nullhypothesis is rejected and it is concluded that the model provides a better fit than the intercept-only model.

Table 5. General linear model for indicating factors affecting actual access time in Group $B\left(R^{2}=0.951\right)$.

\begin{tabular}{|c|c|c|c|c|c|}
\hline Source & Type, sum of squares ${ }^{\circ}$ & Degree of freedom & Mean square & F-test value & $\begin{array}{c}\text { Significance } \\
\text { (P value) }\end{array}$ \\
\hline Corrected model & 16253.000 & 74 & 219.000 & 4.00 & 0.000 \\
\hline Intercept & 16153.000 & 1 & 16153.000 & 366.000 & 0.000 \\
\hline Vehicle ownership & 79.000 & 1 & 1398.883 & 3.859 & 0.000 \\
\hline Sex & 652.000 & 1 & 652.000 & 14.000 & 0.001 \\
\hline Transportation mode & 1740.000 & 3 & 580.000 & 1.817 & 0.000 \\
\hline Income level & 420.000 & 2 & 210.000 & 1.572 & 0.021 \\
\hline Education level & 756.000 & 3 & 252.000 & 2.567 & 0.006 \\
\hline Ethnicity & 582.000 & 3 & 194.000 & 4.000 & 0.016 \\
\hline Patient caregiver & 28.000 & 1 & 28.000 & 3.254 & 0.000 \\
\hline
\end{tabular}

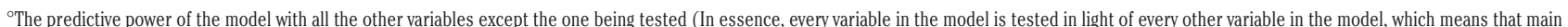
effects are tested in light of interaction variables as well as in light of other main effects). If the P value for the F-test of the overall significance test is less than the 0.05 , the null-hypothesis is rejected and it is concluded that the model provides a better fit than the intercept-only model. 
perfect for examining revealed access to haemodialysis facilities because there are many other non-spatial factors affecting the AAT in rural and urban areas (Tables 4 and 5). For example, patients who live near a haemodialysis facility may have a high AAT score because they do not have access to a taxi or a private car to reach the haemodialysis facility, and this would be because of a poor public transport system or financial problems. Therefore, the AAT compared to driving time is a more comprehensive measurement for health policymakers to target interventions to correctly assign people and places (Figure 3). As both Figures 2 and 3 show, the AAT (as a revealed accessibility index) and driving time (as a potential accessibility index) are different. Additionally, Figure 2 shows that the AAT index determines the outlier patients better than driving time does, so the AAT index can be used for the planning for special patients with special problems. Health policymakers could first identify factors affecting the AAT and then plan to decrease this index because increased access time to haemodialysis facilities could have clinical implications with increased mortality and decreased quality of life (Stephens et al., 2013). According to the Renal Association Clinical Practice Guideline on Hemodialysis, patients in remote areas should have access to haemodialysis facilities as well as be able to return back to their home after finishing treatment within 30 minutes (Mactier et al.,
2011). In our research, $75 \%$ of patients in group A could not access haemodialysis facilities in less than 30 minutes. However, with proper planning, it could be reduced to $25 \%$ (Figure 2).

Unexpectedly, patients in group B, changed their home more often than group A to gain better access to a haemodialysis facility. It seems this is not common in rural areas due to financial problems. Indeed, financial capability is an important non-spatial factor that can affect the AAT to a haemodialysis facility. In this study, the patients with a high income level had a better AAT score. Tshamba et al. (2014) emphasised that the economic status is associated with increased risk of death among haemodialysis patients. Table 3 shows that the total average round-trip cost was 7,000 Toman (about 1.8 USD) for group A and 2,576 Toman (around 0.68 USD) for group B of patients. Although this cost is low in comparison to the full cost for the haemodialysis session (190,000 Toman or close 50 USD), this is not seen by the patients as this cost is fully subsidised by the government. Considering the comparatively low transportation cost, it could perhaps be possible to subsidise that too. This study developed a comprehensive index of revealed accessibility to haemodialysis facilities including spatial and nonspatial factors into one framework. However, the results of this study can only be generalised for regions similar to northern Khorasan. Considering chronic conditions, especially for patients

A

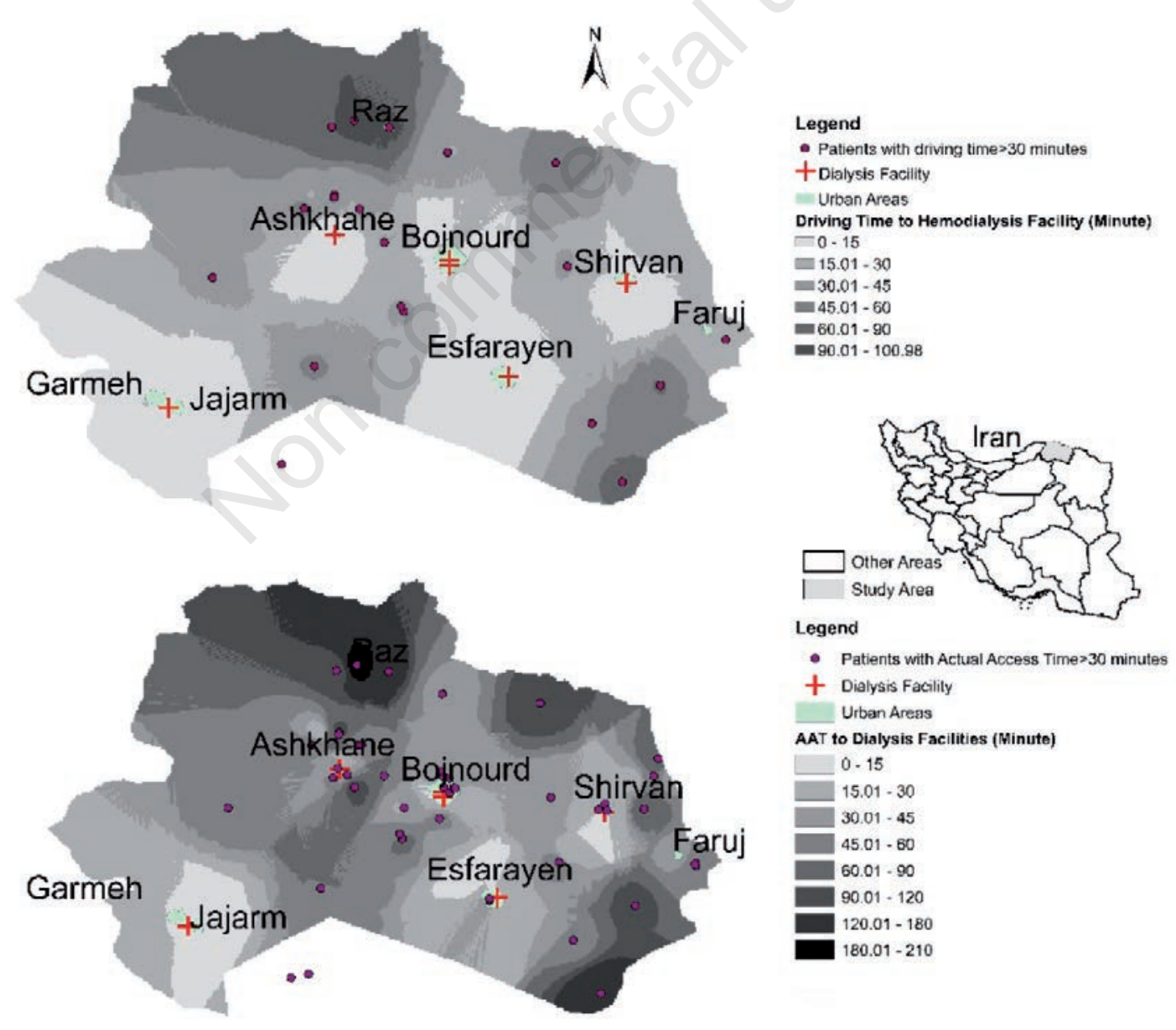

Figure 3. Difference between interpolations of driving time as potential access index (A) and actual access time as revealed access index (B) at the regional levels of north Khorasan Province, Iran. 
with ESRD, the access time to health care facilities and return time travelling home are both important because of the many trips needed to receive the needed health service. Therefore, the ART was also examined. As there was a high correlation between AAT and ART, the policymakers in the health sector should be able to use one of them to improve accessibility to haemodialysis facilities.

\section{Conclusions}

The factors affecting revealed accessibility to haemodialysis facilities are different when rural and urban patients are compared. Policymakers could make proper decisions by analysing the AAT determinants as a revealed accessibility measurement; however, separate analyses are needed for rural and urban patients. Driving time in both urban and rural areas is not a good proxy for measuring access to haemodialysis facilities used alone, as there are many other reasons connected with transportation, for example, women's travel problems, ethnicity disparities, patients' education level, caregivers' status, or low income. As the AAT and ART indices correlate well, policymakers could use any one of these indices to measure revealed accessibility.

\section{References}

Andersen RM, 1995. Revisiting the behavioral model and access to medical care: does it matter? J Health Soc Behav 36:1-10.

Calice-Silva V, Hussein R, Yousif D, Zhang H, Usvyat L, Campos LG, von Gersdorff G, Schaller M, Marcelli D, Grassman A, Etter M, Xu X, Kotanko P, Pecoits-Filho R, 2015. Associations between global population health indicators and dialysis variables in the Monitoring Dialysis Outcomes (MONDO) consortium. Blood Purif 39:125-36.

Casas I, Delmelle E, Delmelle EC, 2016. Potential versus revealed access to care during a dengue fever outbreak. J Transp Health 4:18-29.

Elliott AC, Hynan LS, 2011. A SAS ${ }^{\circledR}$ macro implementation of a multiple comparison post hoc test for a Kruskal-Wallis analysis. Comput Method Progr Biomed 102:75-80.

Faruque LI, Ayyalasomayajula B, Pelletier R, Klarenbach S, Hemmelgarn BR, Tonelli M, 2012. Spatial analysis to locate new clinics for diabetic kidney patients in the underserved communities in Alberta. Nephrol Dial Transplant 27:4102-9.

Guagliardo MF, 2004. Spatial accessibility of primary care: concepts, methods and challenges. Int J Health Geogr 3:3.

Hay AM, 1995. Concepts of equity, fairness and justice in geographical studies. Trans Inst Brit Geogr 20:500-8.

Just PM, de Charro FT, Tschosik EA, Noe LL, Bhattacharyya SK, Riella MC, 2008. Reimbursement and economic factors influencing dialysis modality choice around the world. Nephrol Dial Transplant 23:2365-73.

Kiani B, Bagheri N, Tara A, Hoseini B, Tara M, 2017. Haemodialysis services in the northeastern region of Iran. Geospat Health 12:561.

Lee A, Gudex C, Povlsen JV, Bonnevie B, Nielsen CP, 2008. Patients' views regarding choice of dialysis modality. Nephrol Dial Transplant 23:3953-9.

Lovett A, Haynes R, Sunnenberg G, Gale S, 2002. Car travel time and accessibility by bus to general practitioner services: a study using patient registers and GIS. Soc Sci Med 55:97-111.

Mactier R, Hoenich N, Breen C, 2011. Renal Association Clinical Practice Guidelines on haemodialysis. Nephron Clin Practice 118(Suppl.1):241-86.

Mao L, Nekorchuk D, 2013. Measuring spatial accessibility to healthcare for populations with multiple transportation modes. Health Place 24:115-22.

Matsumoto M, Kashima S, Ogawa T, Takeuchi K, 2013. Do rural and remote areas really have limited accessibility to health care? Geographic analysis of dialysis patients in Hiroshima, Japan. Rural Remote Health 13:2507.

McLafferty SL, 2003. GIS and health care. Annu Rev Public Health 24:25-42.

Miller LM, Vercaigne LM, Moist L, Lok CE, Tangri N, Komenda P, Rigatto C, Mojica J, Sood MM, 2014. The association between geographic proximity to a dialysis facility and use of dialysis catheters. BMC Nephrol 15:40.

Moist LM, Bragg-Gresham JL, Pisoni RL, Saran R, Akiba T, Jacobson SH, Fukuhara S, Mapes DL, Rayner HC, Saito A, Port FK, 2008. Travel time to dialysis as a predictor of healthrelated quality of life, adherence, and mortality: the Dialysis Outcomes and Practice Patterns Study (DOPPS). Am J Kidney Dis 51:641-50.

Mousavi SS, Soleimani A, Mousavi MB, 2014. Epidemiology of end-stage renal disease in Iran: a review article. Saudi J Kidney Dis Transpl 25:697-702.

Murray D, 2008. Dialysis treatment and the impact on transportation services for patients. Kansas Trans Reporter 21:1-6.

Nachar N, 2008. The Mann-Whitney U: A test for assessing whether two independent samples come from the same distribution. Tut Quant Method Psychol 4:13-20.

Neutens T, 2015. Accessibility, equity and health care: review and research directions for transport geographers. J Transport Geogr 43:14-27.

Panel RRH, 2014. Access to rural health care. A literature review and new synthesis. Available from: http://www.rupri.org/newreport-from-the-rupri-rural-health-panel/

Penchansky R, Thomas JW, 1981. The concept of access: definition and relationship to consumer satisfaction. Med Care 19:127-40.

Prakash S, Rodriguez RA, Austin PC, Saskin R, Fernandez A, Moist LM, O'Hare AM, 2010. Racial composition of residential areas associates with access to pre-ESRD nephrology care. J Am Soc Nephrol 21:1192-9.

Roderick P, Clements S, Stone N, Martin D, Diamond I, 1999. What determines geographical variation in rates of acceptance onto renal replacement therapy in England? J Health Serv Res Policy 4:139-46.

Rodriguez RA, Hotchkiss JR, O'Hare AM, 2013. Geographic information systems and chronic kidney disease: racial disparities, rural residence and forecasting. J Nephrol 26:3-15.

Salgado TM, Moles R, Benrimoj SI, Fernandez-Llimos F, 2011. Designing a model to minimize inequities in hemodialysis facilities distribution. Geospat Health 6:5-12.

Saunders MR, Lee H, Maene C, Schuble T, Cagney KA, 2014. Proximity does not equal access: racial disparities in access to high quality dialysis facilities. J Racial Ethn Health Dispar 1:291-9.

Smith MD, Robson AM, Woodward RS, Michelman JE, Valerius 
TJ, Hong BA, 1985. Geographic access to health care services: the case of maintenance hemodialysis. Am J Kidney Dis 5:1926.

Stephens JM, Brotherton S, Dunning SC, Emerson LC, Gilbertson DT, Harrison DJ, Kochevar JJ, McClellan AC, McClellan WM, Wan S, Gitlin M, 2013. Geographic disparities in patient travel for dialysis in the United States. J Rural Health 29:33948.

Thompson S, Gill J, Wang X, Padwal R, Pelletier R, Bello A, Klarenbach S, Tonelli M, 2012. Higher mortality among remote compared to rural or urban dwelling hemodialysis patients in the United States. Kidney Int 82:352-9.

Townsend P, 1987. Deprivation. J Soc Policy 16:125-46.
Tshamba HM, Van Caillie D, Nawej FN, Kapend FM, Kaj FM, Yav GD, Nawej PT, 2014. Risk of death and the economic accessibility at the dialysis therapy for the renal insufficient patients in Lubumbashi city, Democratic Republic of Congo. Pan Afr Med J 19:61.

Wang F, Luo W, 2005. Assessing spatial and nonspatial factors for healthcare access: towards an integrated approach to defining health professional shortage areas. Health Place 11:131-46.

White P, James V, Ansell D, Lodhi V, Donovan KL, 2006. Equity of access to dialysis facilities in Wales. Qjm 99:445-52.

Wikipedia, 2016. Wikipedia page on North Khorasan Province. 2016. Available from: https://en.wikipedia.org/wiki /North_Khorasan_Province 